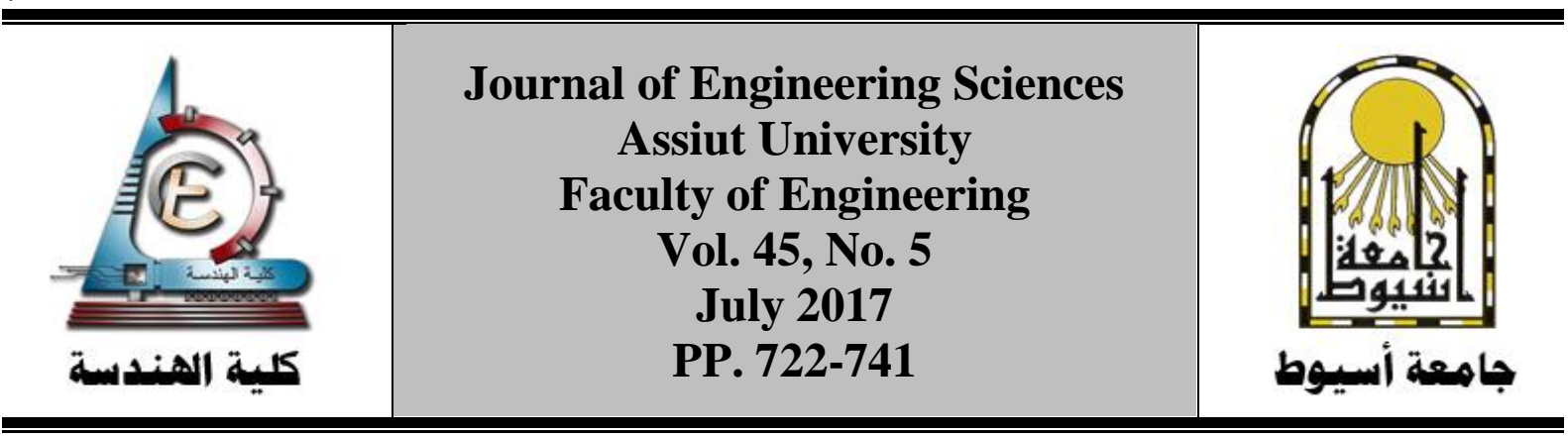

\title{
STUDYING THE INDOOR AIR POLLUTION WITHIN THE RESIDENTIAL BUILDINGS IN EGYPT AS A FACTOR OF SUSTAINABILITY
}

\author{
Usama Konbr \\ drusamakonbr@f-eng.tanta.edu.eg \\ Department of Architecture, Faculty of Engineering, Tanta University, Egypt. \\ Received 25 July 2017; Accepted 29 August 2017
}

\begin{abstract}
The paper proposed a framework to address indoor air pollution within the residential buildings in the architectural scope. This framework was handled in two phases. The first phase addressed the technical solutions divided into categories, subcategories, and strategies (solutions). The second phase is the framework's activation, which came through an assessment tool's extraction. This tool is formed in a comprehensive, configurable, and multidisciplinary checklist. This checklist covers the overall technical solutions' categories and subcategories. Then, it conducts the strategies to specific \& measurable indicators by setting maximum points for each indicator. Assessment of indicators depends on the relative importance, which set depending on the specialists' teamwork. The proposed checklist can help both designers and evaluators in both design \& assessment phases. Officially, it can be activated through multidisciplinary specialist's teamwork. Hence, certified licenses can be released. Activation needs to establish a specific \& official authority to assess the concluded indicators. Hence, it can be used as a part of the licensing requirements for new projects before its awarding regarding IAQ. Also, evaluators can use it to assess the existing projects. Then, the study findings represent a step to study indoor air pollution and to promote sustainability.
\end{abstract}

Keywords: Indoor Air Pollution; Indoor Air Quality (IAQ); Residential Buildings; Sustainability.

\section{Introduction}

People usually spend around $90 \%$ of their daily time indoors. Related to residential buildings, occupants spend between $53-82 \%$ on them. Therefore, the quality of the indoor environment is an essential determinant of people's health [1]. Also, indoor air pollution as a problem is vital to be addressed. This refers to the pollution output rates, which reach tens of times compared with the outdoor pollution. Indoor air pollution increases due to the rising use of manufactured building materials, finishes, furniture, HVAC systems, various building chemicals, etc.

The scientific outcomes, particularly in Egypt, the IAQ concerns in residential buildings still have slight care. The paper aims to study the aspects \& factors of indoor air pollution through a framework in two phases. Phase one proposes the technical solutions extracted to address the most repeated issues of the research problem. 
Usama Konbr, Studying the indoor air pollution within the residential buildings in Egypt

The second phase aims to discuss the framework's activation. It comes from extracting a tool to summarize the strategies addressed inductively, then reaching the corresponding and concluded indicators. Hence, the consentient specialist's teamwork can measure these indicators in more detail where it relies on scientific data and equipment, as it was executed in similar approaches abroad. The framework in two phases helps as a starting step in this scientific area in the actual Egyptian scope. Fig. 1. illustrates the sequence of the study and the research skeleton.

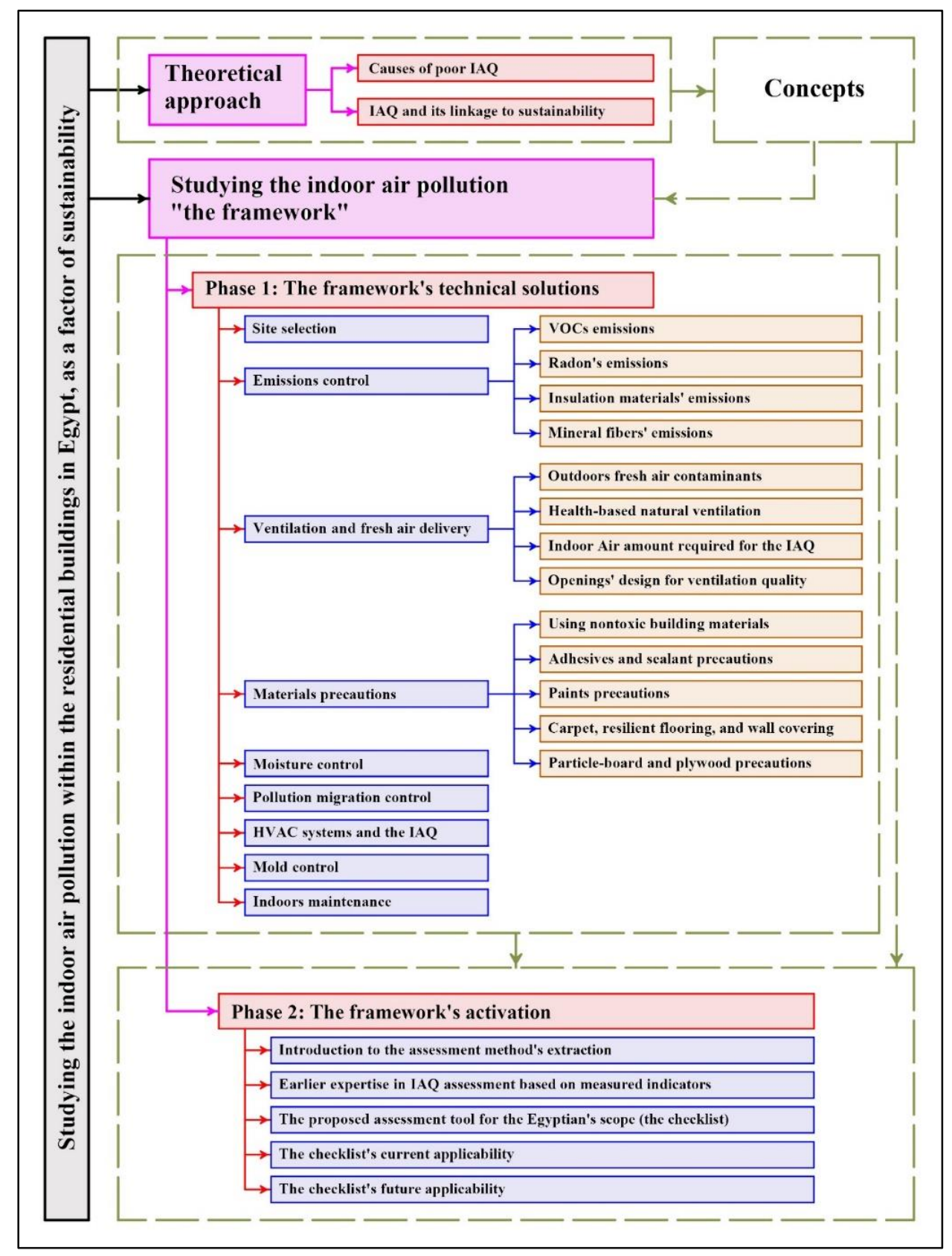

Fig. 1. The research skeleton

\section{Method}

The trend of the research problem led to the use of the induction method. Mainly, the research sections depended on the authoritative, professional, academic books \& reports, specialized scientific journals, and academic theses. Chronologically, the references were chosen to be up to date, to understand the research problem with the existing relationships between the various sub-phenomena of the basic phenomenon. Also, the Deduction method is used to extract the 
JES, Assiut University, Faculty of Engineering, Vol. 45, No. 5, September 2017, pp. 722-741

proposed checklist, which helps with concluding the indicators based on the strategies of the most repeated aspects. Also, a Mathematical method is set to measure the indicators, depending on both points \& the relative importance's method.

\section{Theoretical Approach}

It comes in two straightforward approaches as a concise preface to the proposed framework.

\subsection{Causes of poor IAQ}

The studies in the last decades confirmed that the leading causes of poor IAQ are:

$52 \%$ inadequate ventilation, $16 \%$ contamination from inside buildings, $10 \%$ contamination from outside buildings, $5 \%$ microbial contamination, $4 \%$ pollution from building fabric, and $13 \%$ from unidentified sources [2].

Pollutants cause poor IAQ from varieties of sources, including outside air. It can be considered as any cause that reduces the comfort and health standard of the IAQ. Moreover, it includes overheating through solar gain, humidity, dust, and microbes, etc. As shown in Fig. 2 [3].

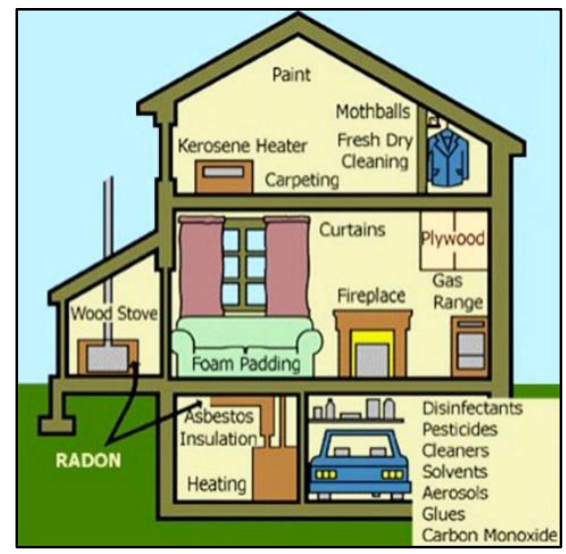

Fig. 2. causes of poor IAQ

\subsection{IAQ and its linkage to sustainability}

Integration of the IAQ considerations in sustainable designs suffers from the insufficiency of comprehensive and information-based assessment methods. Guidance and rating systems for "green" buildings fail to handle the compromises necessary for assessing the building performance [4].

Lately, various tools are developed to assess the ability to measure the greenness of buildings [5]. It depends on setting the various efficiency aspects, design points, and indices. It is typically classified into six main categories: site planning, water management, energy management, material use, indoor air quality, and Innovation \& Design. Therefore, it explains the importance of the IAQ as a significant pillar of the Indoor Environmental Quality (IEQ), and in this way for encouraging sustainability.

\section{The Framework of "Studying the Indoor Air Pollution"}

It comes in two phases. The first phase is the framework's technical solutions, and the second is the framework's activation. The two phases are detailed as follows:

\subsection{The framework's technical solutions}

Technical solutions are the first phase of the framework; it attempts to guide materials, designs, and procedures for avoiding indoor air pollution. It comes with leading nine technical solutions 
Usama Konbr, Studying the indoor air pollution within the residential buildings in Egypt .........

(categories). It handles the main concerns and explores the most repeated approaches for preventing or minimizing indoor air pollution. It is divided into nine main categories, which branched into subcategories detailed through strategies (technical solutions). This phase details can be explained in Fig. 3 .

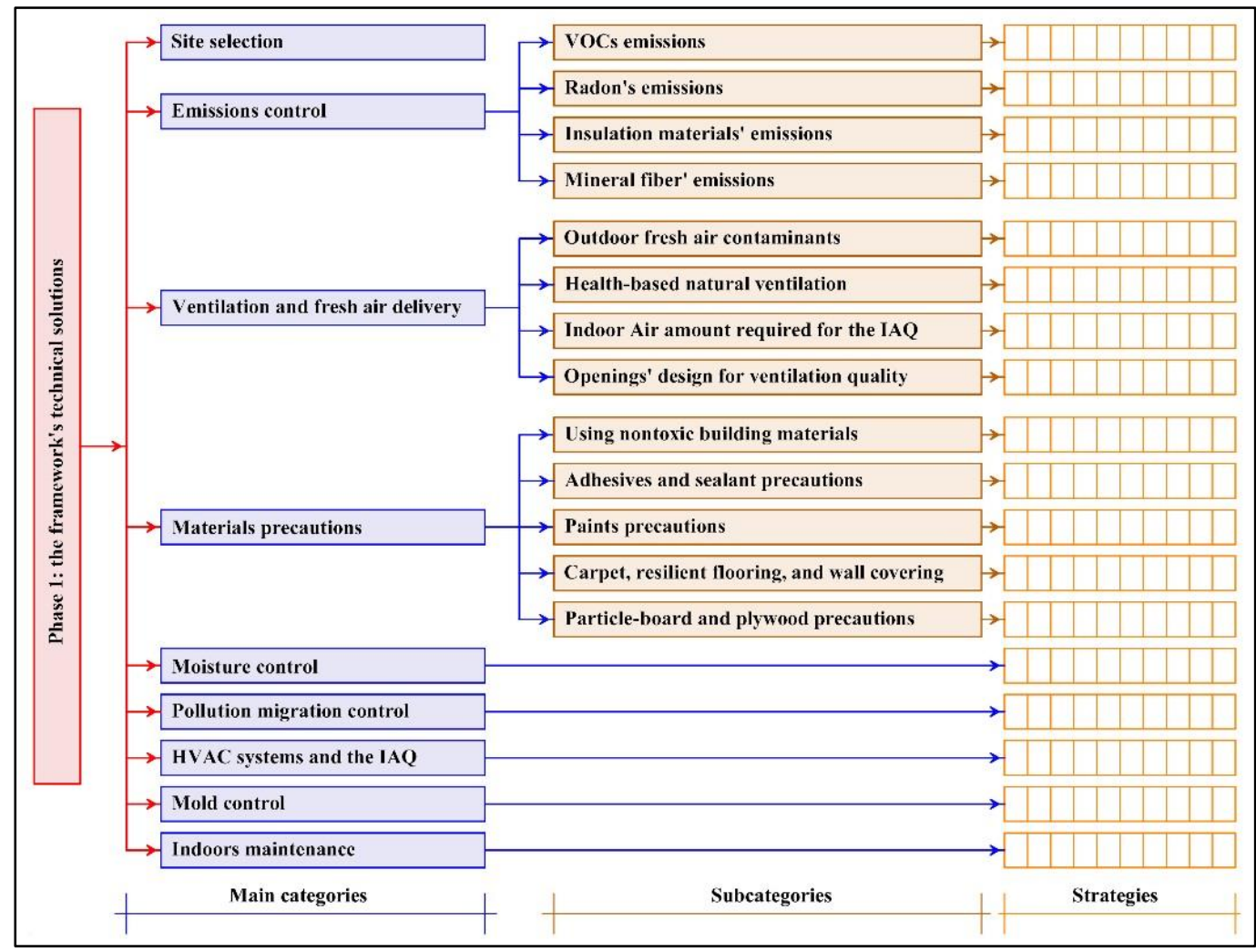

Fig. 3. Phase 1: the framework's nine technical solutions

\subsubsection{Site selection}

It is the first category. It handles the following factors of the site's circumstances that affect the IAQ. These are [6]:

- Local geography, regarding the site ridges, mountains, and water masses.

- The ambient rural context through agrarian abuses, gardens, arid soils, and irritants, etc.

- Urban context through the remains, vicinity to trash dustbins, and adjoining building exhaust influence the fresh air intakes, Fig. 4.

- Transportation runs out from streets, low emitting \& fuel-efficient vehicles, parking garages' capacity, railway tracks, terminals, etc.

- Public transportation access and bicycling [7].

- Industrial enterprises with their ingredients and impacts \& pollution reduction control.

- Undesired soil gases \& fumes, like Radon, leakages, and earlier harmful usage of the site.

- Passive adjacent construction activities with a threat or semi-hazardous materials, like bitumen and asbestos.

So, the urban forest concept can be considered about urban and site solutions to reduce air particles [8].

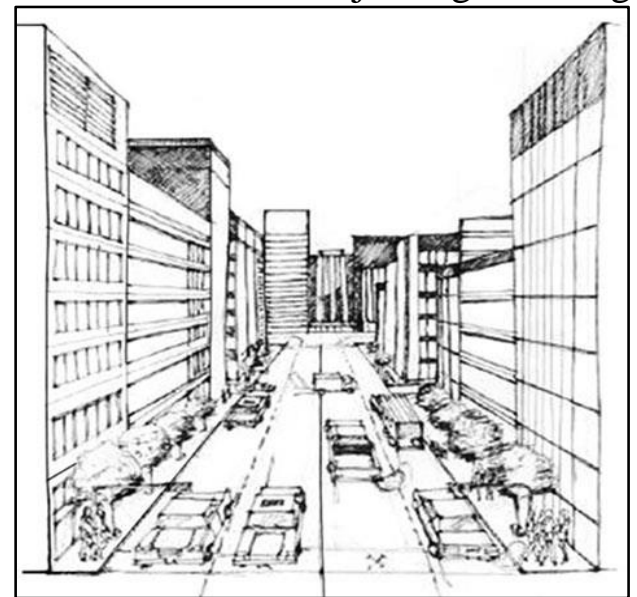

Fig. 4. effects of dense surrounding urban context on the IAQ 


\subsubsection{Emissions control}

It is handled in four subcategories as follows:

\subsubsection{VOCs emissions}

The Volatile Organic Compounds (VOCs) contain all chemicals that have carbon and hydrogen. Types of indoor decorations, coats, and other building materials can produce it through paints, solvents, adhesives, matters, fabrics, and fibers. Odors associated with an increase of VOCs resemble those linked to the above matters. The increasing variety of possible causes and contents renders it impractical to test each chemical's concentrations alone. So, the way of total VOCs attempts to deal with this practical control. A simple test of the total VOCs can be executed without the separation between individual compounds [9].

Controlling VOC concentrations pose a specific difficulty where filtration and source control are crucial. This refers to VOCs' many origins in buildings, including construction materials, furnishings, and cleaning supplies. The broad potential of VOCs inside buildings makes individual measurements difficult and expensive. As a result, the most common way of handling is to end their sources. Then, it should be decreased, whatever concentrations stay with outdoor air.

\subsubsection{Radon's emissions}

Radon can enter the indoors, as shown in Fig. 5, through [10]:
A. Cracks in concrete.
B. Spaces behind walls.
C. Pores \& cracks in blocks.
D. Floor.
E. Wall joints.
F. Exposed soil as in a sump.
G. Weeping tile.
H. Mortar joints.
I. Penetrations of a loose-fitting pipe.
J. Walls' open tops.
K. Foundations.
L. Well water.

Hence, radon-resistant can be handled through:
A. Gaseous porous layer.
B. Plastic sheeting.
D. Vent Pipe.
E. Junction box.
C. Sealing and caulking.

Other radon reduction techniques can include sealing, room pressurization, heat recovery, and natural ventilation, as illustrated in Fig. 6 [11].

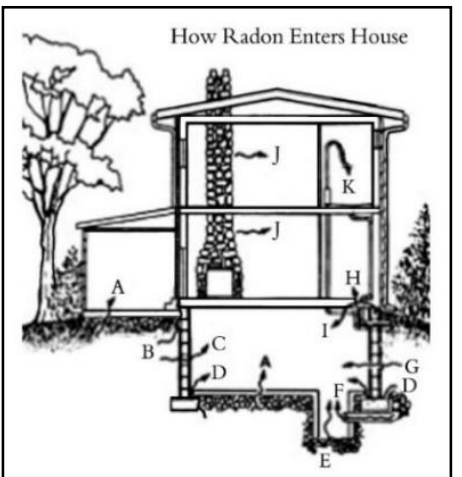

Fig. 5. radon sources

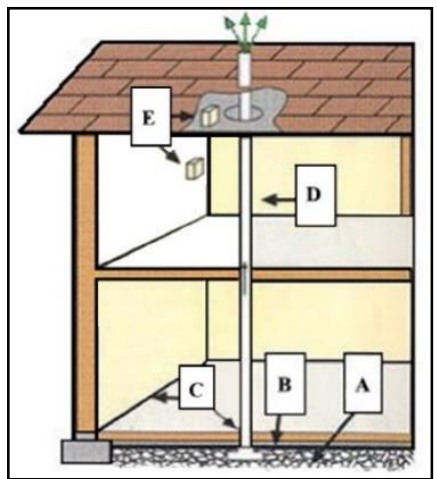

Fig. 6. radon resistant (construction

\subsubsection{Insulation materials' emissions}

Insulators are among the most common health problems in buildings, especially those responsible for high formaldehyde levels. Industrial foam produces many highly toxic gases when heated or burned. It forces people to use protective masks when exposed to such insulators' incineration or the occurrence of indoor fires. Most deaths from building fires are 
Usama Konbr, Studying the indoor air pollution within the residential buildings in Egypt .........

due to carbon dioxide released from the insulation components' incineration. So, most of the construction's requirements \& codes need to keep the occupants' insulation materials away. Also, fire-resistant material should be considered . For example, gypsum is advised [12].

\subsubsection{Mineral fiber's emissions}

Fine mineral fibers include mineral fiber emissions from facilities, manufacturing or processing, glass, rocks, or slag fibers. It is embodied in this description the synthetic vitreous fibers, which consist of, glass wool, rock wool, slag wool, glass filaments, and ceramic fibers.

Acute short-term influences of fine mineral fibers in people did not go on after exposure ceased. Hereabouts, the investigations have reported a rise in lung tumors in animals exposed to ceramic fibers by inhalation. No increase in tumors was recorded from exposure to glass wool, rock wool, or slag wool. Environmental Protection Agency (EPA) has classified refractory ceramic fibers as probable human carcinogens.

The National Toxicology Program (NTP) [13] categorized glass wool fibers as moderately predicted to be a cancer cause [14]. Using these fibers needs specific attention to design, solutions, and details to manipulate these emissions to the outsides through natural ventilation.

\subsubsection{Ventilation and fresh air delivery}

In this context, ventilation can be defined as the air supply from outside to indoors to reduce indoor air pollution and treat the Sick Building Syndrome (SBS) [15]. That depends on the occupation and the pollution ratio (ventilation rate/capita) through the fresh air quality. Both quantity of air \& precautions of mechanical devices and the architectural openings' design can adjust the ventilation. This category is addressed through four subcategories as follows:

\subsubsection{Outdoors fresh air contaminants}

It is around $10 \%$ of total cases of SBS. Overzealous energy-saving procedures are often the direct cause of inadequate fresh outdoor air which enters ventilation systems.

Smog is large-scale outdoor pollution, primarily caused by automobile exhaust and industrial emissions. Cities are significantly considered as centers of these kinds of activities. It suffers from the impacts of smog, especially during the warm months.

The precise reasons for pollution in cities vary depending on temperature, geographical location, wind \& weather factors, and pollution, which are scattered differently. Occasionally, it does not occur, and the air pollution can increase to risky ranks [16].

Contaminant sources as sanitary vents, cooling towers, vehicular waste from parking garages, landing docks, and traffic should be obviated. Also, special care should avoid moisture types from cooling towers into the makeup air and building vents. Even the outdoor air of acceptable quality can become contaminated if brought into the building through contaminated outdoor air intakes and duct-works [17].

\subsubsection{Health-based natural ventilation}

Noteworthy, inadequate ventilation causes around 52\% of SBS [18]. The heat balance can consider human comfort and ventilation through indices and models. Indoors, the required amount of oxygen is necessary to stop the increase of carbon dioxide \& unwanted odors. Additionally, to reduce the amount of carbon monoxide \& other combustion products to a level below the level that harms health. Then, smoking pollution should be considered.

As known, air quality results from a range of factors, as the concentration of carbon dioxide. Calculating the amount of fresh air per person per hour $(\mathrm{Q})$, on condition that the concentration 
JES, Assiut University, Faculty of Engineering, Vol. 45, No. 5, September 2017, pp. 722-741

of carbon dioxide does not increase over $0.5 \%$, needs the following equation [19]:

$\mathrm{Q}=\mathrm{q} .100 /(0.5-0.05) \times 1000=\mathrm{q} / 4.5 \mathrm{~m}^{3} / \mathrm{h}$ per person. Where, $(\mathrm{q})$ is emission rate $\left(\mathrm{m}^{3} / \mathrm{h}\right)$.

If the production of carbon dioxide is about $181 / \mathrm{h}$ in the case of dormancy, then:

$\mathrm{Q}=4 \mathrm{~m}^{3} /$ hour / person.

However, with manual labor, the production of carbon dioxide is 54 liters/hour.

Then, $\mathrm{Q}=12 \mathrm{~m}^{3} /$ hour $/$ person.

These rates are not enough for the odors Impact's mitigation. The aim of ventilation is not to have unacceptable odors in a significant amount of buildings but to ensure minimum ventilation requirements essential in kitchens, bathrooms, and toilets. So, connection to the outdoors is needed.

Last, by taking carbon monoxide into account, the smell's standard is not the only matter needed, but more ventilation is required, where carbon monoxide gas is still toxic, even if at small concentrations. Then, limiting it in the residential building is considered as $0.01 \%$ [20].

\subsubsection{The indoor Air amount required for the IAQ}

It is considered by studying contaminants, ventilation rates, air change effectiveness $\&$ age of air, ventilation systems, and energy needs for ventilation. Calculating air infiltration needs taking air leakage characteristics of buildings, modeling studies, and measurement steps [21].

Unsatisfactory ventilation can occur if the HVAC systems do not passably distribute the air in buildings. Till about the middle of the $1900 \mathrm{~s}$, building ventilation standards were defined around 7.08 liter/s of outside air /person to reduce \& remove odors. Later, a decrease in the outdoor air provided for ventilation reached $2.36 \mathrm{liter} / \mathrm{s} /$ person to achieve satisfactory IAQ with reducing energy amount used. Lately, the ventilation standard is changed by ASHRAE to be a minimum of 7.08 liter/s of outdoor air /person. Up to 28.137 liter/s/person may be needed in the zones like the smoking lounge, depending on the activities in these spaces [22].

\subsubsection{Openings' design for ventilation quality}

Openings and their shapes should be studied to ensure efficient performance in terms of transition or thermal insulation, lighting, and effective solar radiation treatment. So, reference can be made relying on several climatic control studies to prove its impacts on the indoors. It can come in terms of shapes, measurements, and orientation, etc.

The typical windows (solar, glass, and wire mesh) deal with this point successfully, mainly if many other criteria are considered, such as IAQ, ventilation, shading, air conditioning control, privacy, and preventing harmful insects.

Also, the windows with fine details, Fig. 7, can control both indoor and outdoor air, where openings can be used in some cases, as:

- Increased outdoor pollution at a high rate.

- There is over one source of pollutions, such as high outside noise.

- Confronting spread of fungi and chemical contaminants, or others caused by microorganisms from the ambient environment.

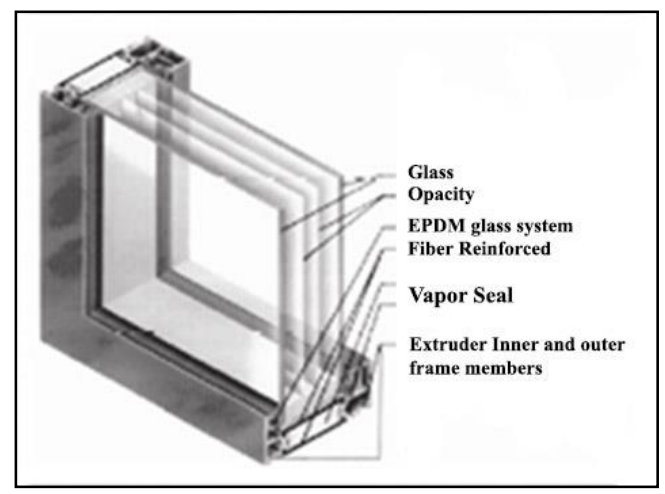

Fig. 7. openings details for ventilation 
Usama Konbr, Studying the indoor air pollution within the residential buildings in Egypt ..........

\subsubsection{Materials precautions}

According to LEED, the Indoor Environmental Quality (IEQ) takes 15/69 points. Only materials as a specific indicator take 4/15 points of them. The material takes 13/69 (total possible points) [23]. So, it gives a clear result by its importance. Hence, for the IAQ, it can be detailed in 4 essential points as follows:

\subsubsection{Using non-toxic building materials}

The environmental effects should be studied over the life-cycle where that material emits contaminants that may be shortened or extended to the buildings' whole age. For example, adhesives, types of glue, chemicals, formaldehyde, benzene, and ammonia can cause harmful impacts to occupants [24]. So, products that contain solvents, glues, and plastics are not preferred.

Noteworthy, there is an increasing number of commercial sources of natural paints, glues, materials, and systems. Economically, it can be substituted, but it has a dangerous impact as a building material, for example, particleboard, wafer board, carpet, foams, and paint. Also, Decreasing the entire VOCs intensities with considering the size needs may need, for example, using the natural (and unpainted) lime-cement plaster, sand, and solid wood as wall finishes. Similarly, concrete, linoleum, solid wood, and ceramic tiles for floor finishes can also be used.

It is safer to use organic adhesives with fewer VOCs and chemically based emissions. It includes aromatic solvents with little or no odor during manufacturing, construction, and disposal stages [25]. Finally, they must also avoid material and products that might affect the IAQ about occupants and maintenance staff.

\subsubsection{Adhesives and sealant precautions}

It can be used wet and dry or for curing on the premises, wherever the solvents used in the preparation of these materials are directly related to the produced VOCs. The resins used in the base of adhesives are natural or synthetic, and it ranges from low to high rates of emission. Sealants that consist of putties, caulking compounds, rubber, acrylic latexes, and silicones should be carefully taken about emissions. Similarly, paints, stains, sealers, and varnishes used in coatings should be considered [26]. Cracks and joints are weak points in IAQ handling. It requires adhesives and sealant to decrease infiltration \& conditions contributing to pest access and mitigates the Radon's impact [27].

Some architectural works include wood flooring, carpet pad adhesives, rubber floor, ceramic tiles, subfloor, asphalt, multi-purpose construction, drywall \& panel, and structural glazing for all these VOCs Limits must be considered according to the standards [28].

\subsubsection{Paints precautions}

These precautions should be taken to handle architectural paints, coatings, primers, anticorrosive, anti-rust paints, clear wood finishes, floor coatings, stains, and shellacs must follow low VOC emissions. Furthermore, it recommended that paints should be implemented during empty periods and fast-drying paint as workable. It is recommended that keeping lids on paint containers when not in use.

The buildings' ventilation should also be kept through large amounts of external air during and after the paint and ensure the entire airflow out before occupancy. Recommend ventilation at higher rates than usual for a period after occupancy and avoid spraying whenever possible, preferably using water-based paints, natural materials, or composite materials with low emission ratios. 


\subsubsection{Carpet, resilient flooring, and wall covering}

Using adhesives to attach the material to various surfaces can bring VOCs into the indoors. The floors are usually poured concrete and often covered with vinyl tile, terrazzo, or carpet. Vinyl and asbestos tile were widely used lately in new buildings; floor coverings are glued-down industrial-grade carpeting. Emissions from carpeting and associated adhesives have been the IAQ complaints in buildings where carpeting becomes a sink for a wide diversity of organic particles [29].

Acoustic treatment materials, carpets, upholstery fabrics are considered the most absorbers for organic compound emissions /unit area. So, some details for floors Fig. 8. can be done to achieve the integration between ventilation studies and the IAQ through the lifted floors technique. Where it can be covered with natural materials or any other suitable coverages [30].

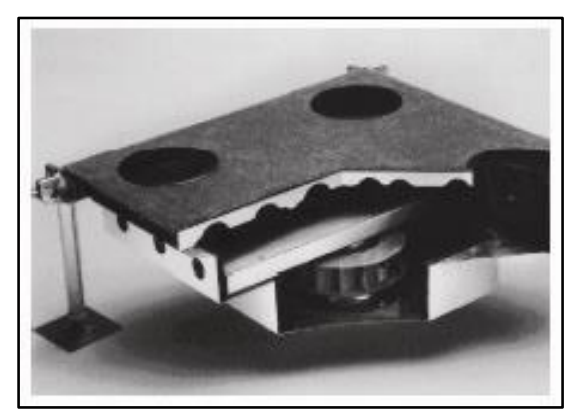

Fig. 8. VOCs emissions control through floor ventilation's details

\subsubsection{Particle-board and plywood precautions}

Particleboard is a composite product made from wood chips or residues that are bonded together with adhesives. Typically, it comes from milling or woodworking waste. Plywood is made up of thin sheets or layers of wood which glued with adhesive. It is categorized as softwood \& hardwood. Substantially, the IAQ is affected by softwood and hardwood, where its characteristics are varied with the adhesives [31].

Hardwood unusually has more effects on IAQ compared with softwood. Hardwood is glued with urea-formaldehyde adhesives, which release formaldehyde for months or years later of production. Phenol-formaldehyde adhesives, commonly used in softwood, are steadier and have minor formaldehyde emissions. Usually, softwood can be used in the exterior [32].

\subsubsection{Moisture control}

Moisture control in building assemblies can be done by limiting liquid water penetration into the building envelope and limiting water vapor condensation. Also, it can be done on interior surfaces by maintaining proper building pressurization, controlling humidity, selecting suitable materials, equipment, and assemblies for unavoidably wet areas. That also considers the impact of landscaping and indoor plants on moisture and contaminant levels.

Also, for mechanical systems and Bath's zone, moisture control should be considered, where dirt in air handling systems, piping, plumbing fixtures, and duct-works should be examined. Besides, facilitating HVAC access for inspection, cleaning \& maintenance, and legionella control in water systems need more care [33].

As well, possibly to rely on porous materials without covering or coating them with paints that fill their pores. So, it helps retain the moisture in its pores at night and releases it in the daytime. Also, it helps in improving the IAQ and causing thermal comfort as well. For example, of the materials not covered with paints, like bricks, natural stones, and wood, especially if indoors' relative humidity is within $85 \%$ [34].

\subsubsection{Pollution migration control}

The architect should conceptualize the indoors' zones to limit their effects on each other. For example, as shown in Fig. 9, the kitchens should be protected from fumes, odors, and emissionsrelated food preparation systems [35]. The disposal of waste from bathrooms should be 
Usama Konbr, Studying the indoor air pollution within the residential buildings in Egypt .........

separated from the living \& the sleeping zones to prevent odors and unhealthy \& undesirable emissions emitted by them. These spaces' placement should be set under wind influence. Then, leakage can be directed to outdoors.

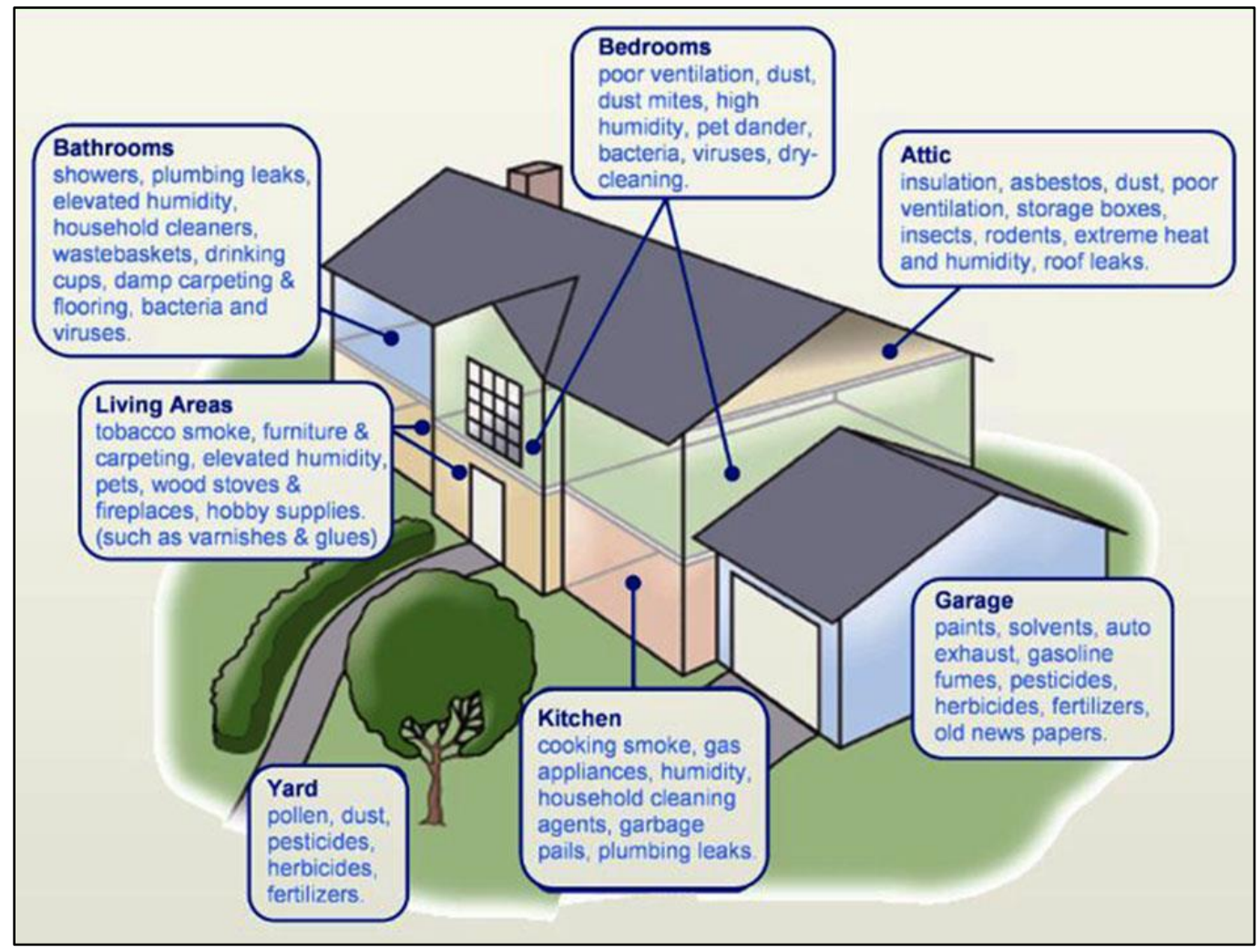

Fig. 9. the IAQ particulate sources

Residential buildings may also include specific needs in terms of tools \& activities, such as imaging tools, computers, or those based on radiation. These can impact the IAQ and its characteristics. So, the environmental aspects of that equipment about its technical specifications, and methods of use should be taken over the choice of species having certificates or licenses. Using it later than passing the tests of the quality \& performance is essential.

\subsubsection{HVAC systems and the IAQ}

The operation and maintenance of HVAC systems play a critical role in maintaining acceptable IAQ and thermal comfort at a reasonable energy cost. Fail of its design, installation, commission, operation, and maintenance may lead to IAQ complaints.

Then, supplying conditioned air to indoors at an adequate outdoor air delivery rate is needed. The quantity or distribution of adequate outdoor air, which serves the ventilation, is needed. Under conditions of inadequate outdoor air ventilation, human bio-effluents and other indoor contaminants may build up indoors to levels that may affect health or comfort.

HVAC systems can also play a role in distributing contaminants to the occupied spaces from external sources or other internal sources. Also, it can be a cause of pollution, if not well preserved. Internal rusting, debris accumulation, and deterioration of internally insulated surfaces can lead to infiltration and distribution of these contaminants into the supply air stream. Stagnant water sources can also cause microbial growth. So, essential to maintain the HVAC systems regularly [36]. 
JES, Assiut University, Faculty of Engineering, Vol. 45, No. 5, September 2017, pp. 722-741

Prevention or remediation of indoor air pollution requires optimizing geometrical configurations, understanding HVAC systems, perceived or anticipated contaminants, source areas, and economics [37]. Generally, achieving HVAC quality needs [38]:

- Establishing a maintenance plan.

- Inspection of HVAC Systems regularly.

- Checking, cleaning, and changing filters according to the manufacturer's instructions and ensuring that condensation pans are draining.

- Providing outdoor air ventilation according to ASHRAE standards or local codes.

- Cleaning of air supply diffusers, return registers, and outside air intakes.

- Keeping the unit ventilators clear of books, papers, and other items.

\subsubsection{Mold control}

For mold and other allergens, the indoor humidity should be kept at roughly $30-50 \%$. Also, using dehumidifiers to reduce moisture can help. Exhaust fans should be used when cooking, bathing, fixing leaks, and other water problems right away.

Some precautions about architectural elements:

- Hidden leaks behind walls must be fixed in the living rooms' walls.

- Using exhaust fans or openings' windows for showers and excessive moisture needs.

- Care should be given to fixing leaks or water damage quickly for roofs, wet spots, or water stains.

- Paint must not be done over wet or moldy walls at bedrooms' corners.

- Water from a roof leak seeped into the walls causes the paint to buckle and peel.

- The stove exhaust hood should draw heat, moisture, and other contaminants at kitchens' walls.

- Drain gutter length should have a suitable length to pump out the rainwater away to keep water away from the foundations.

- The ground near buildings should be sloped downward to drain water away from it at the yard [39].

\subsubsection{Indoors maintenance}

Maintaining buildings' hygiene is essential to ensure the IAQ healthy. Regular cleaning of the building is necessary to avoid the accumulation of debris and particulate matter buildup. The cleaning material may contribute to indoor air pollution if it is based on chemicals or solvent. Besides, the scheduling of maintenance activities should occur during periods in which the buildings are unoccupied [40].

In general, some elements need maintenance, e.g., filters \& air-cleaning devices, outdoor air dampers \& actuators, humidifiers, dehumidification coils, drain pans, and other adjacent surfaces. That is subjected to the outdoor air inlet louvers, which cause wetting, bird screens, fog eliminators, and nearby components. Likewise, air handling systems except for units under $2,000 \mathrm{cfm}$ (944 liter/s), cooling towers, and floor drains are taken as guides [41].

\subsection{The framework's activation}

the study directs it through a designed checklist tool to convey the above theoretical framework into the activation phase. It has some indicators, which influence the research problem. This checklist can help in the performance's assessment about the indoor air pollution as follows: 
Usama Konbr, Studying the indoor air pollution within the residential buildings in Egypt .........

\subsubsection{Introduction to the assessment method's extraction}

The environmental assessment aims to postulate, predict, and degree the performance of the residential buildings. It can be highlighted in long-term operational benefits and give a valuable marketing tool for the construction industry, increasing the demand for environmental quality. Then, it can promote sustainability in this sector.

Globally, many environmental assessment methods already in use. It varies in harmony with local conditions and stakeholders' concerns. These methods are sharing similar features $\&$ goals.

Several preceding studies for the IEQ tools, assessment models, classification indicators, and schemes for evaluating the IEQ are there. Many countries already have or in the developing phase of preparing their domestic assessment methods, which need international exchange and coordination in the same scope.

Most of the sustainability assessment systems do not contain conjoined social, environmental, or economic principles. However, it has a various dialect, it ahead toward resources' regard and environmental standards. However, it dominates the socio-economic problems and weighting credits. At the same scope, an earlier paper [42] provided an overview of sustainability assessment to rate the IEQ. It stated that "no best tool" is set for assessing sustainability. Where, Fig. 10. shows significantly varied weights of the IEQ in the various systems. The differences range from $6.67 \%$ to $30.6 \%$. So, these systems' assessment gives a clear difference in the results. Moreover, it is uncertain and deficient.

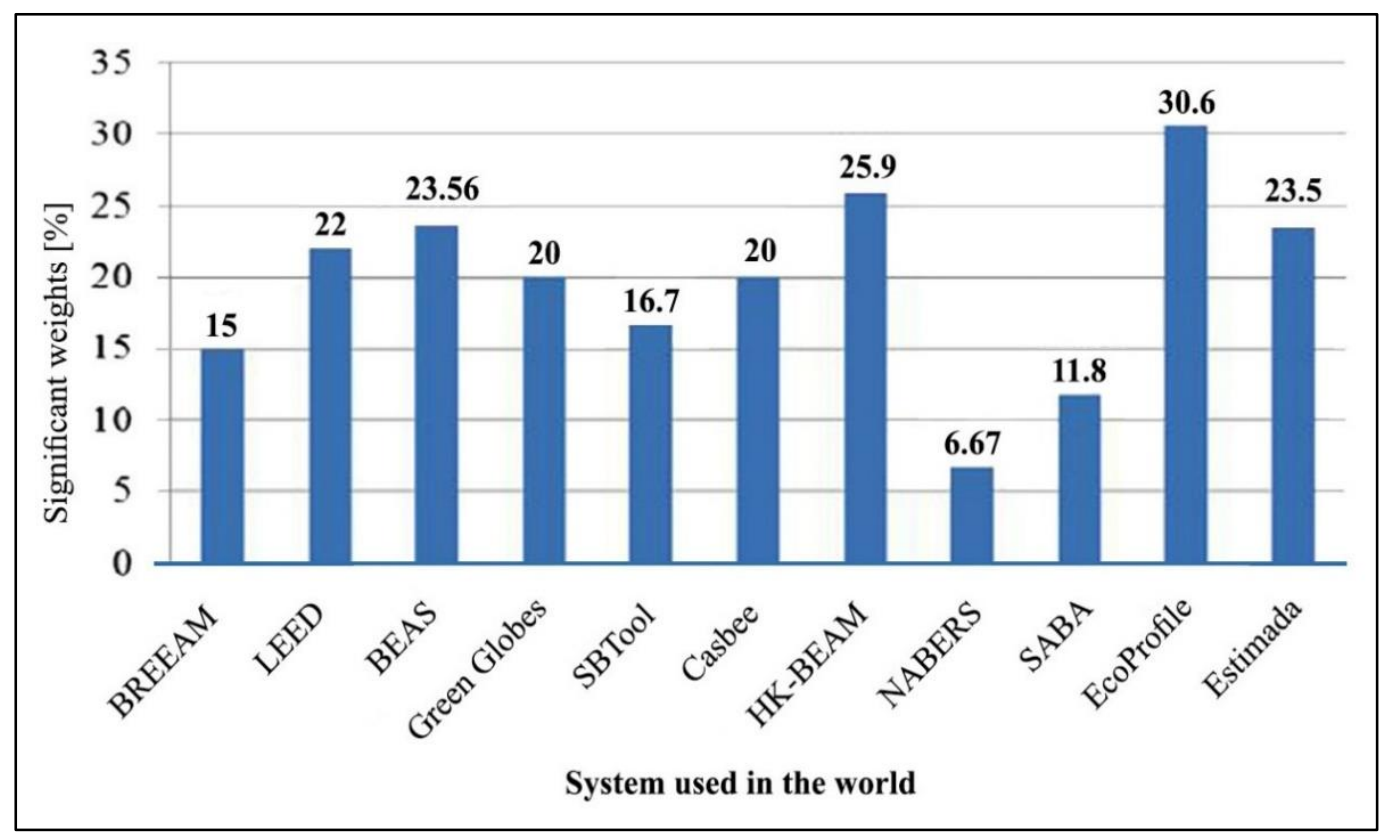

Fig. 10. Percentage weights of the IEQ in the different systems

Hence, the IAQ assessment is complex because it contains broad criteria and many specialists that continuously vary over time and space. The IAQ indicators can classify, describe, and improve IAQ by providing precise and comprehensive grades of IAQ points to address this complexity.

Over and above, sustainability is based on the three top pillars, which impose a change in the relative weights of the different criteria according to the assessment locality. So, the existence of unchanging global standards seems to be unacceptable. However, the criteria can be systematically defined and categorized in specific indicators to allow both review and 
assessment. Hence, certification can be done, depending on various professional specialists in each category.

\subsubsection{Earlier expertise in IAQ assessment based on measured indicators}

In an earlier study, six measurement-based IAQ indexes were proposed in the USA, France, Taiwan, and Hong Kong. The assessment was based on nine parameters only [43].

This study aimed to make a comparison between the methods of IAQ assessment in these countries. Also, it compared every level related to the specific six indexes, where levels are divided into classes. The study showed that only three indexes were repeatable, While the other three indexes were more different regarding the final findings. The cause refers to some indexes that contain classes that were not associated with IAQ classification. So, it led to bias in the analysis. It can be understood through [44]:

- The objectives of the selected indexes, which were diverse and not consistent.

- Indexes dataset, which omits some parameters measurement. So, it partially evaluated these indexes. Therefore, more bias happened.

- Unclear recording of indexes' sampling period, then, the final assessment's calculation had an error.

Therefore, this study could not wholly replicate the primary indexes, where the above three defects led to an assessment calculation bias as indexes could not be quantified. Moreover, some indexes' challenges remain, where the parameters should rely on the objectives, the parameters, and the indexes, which must be clearly defined.

Despite the great efforts proposed by this specific and international teamwork, finally, the teamwork himself considered these findings just as an exploratory study. It stated that it is only a phase to develop an integrative indicator for the IAQ defining and increase awareness.

\subsubsection{The proposed assessment tool for the Egyptian's scope (the checklist)}

There is a vital necessity to develop tools for the IAQ assessment. The paper aims to benefit from the inductive handling of the IAQ in Phase 1 in formalizing a systematic and categorized tool hierarchically. Also, it assembles the most repeated issues of the research problem within a configurable method; this tool is represented in an execution checklist. It consists of some of the extracted indicators (guidance) used comprehensively in residential buildings in Egypt. It activates all disciplines required through a configurable evaluation method, where the final record is based on the collective specialist's team's opinion. It determines the relative importance and maximum degree available of indicators permitting measuring the result achieved for each indicator individually. Lastly, the final assessment will come out, as shown in Table 1.

The emerged assessment result must be detailed in a report of the walk-through outcomes. It must also rank and categorize the records of the recommended improvements of the present IAQ shortages in the tested sample. So, it can act as a factor in improving the performance. Then, personnel can choose the most suitable decisions for the client through the given recommendations. The checklist can give suitable participation in adopting that practice for improving the IAQ through its professional teamwork. 
Usama Konbr, Studying the indoor air pollution within the residential buildings in Egypt .........

Table 1.

The assessment checklist (technical solutions' categories \& subcategories and Concluded indicators)

\begin{tabular}{|c|c|c|c|c|}
\hline \multirow[t]{2}{*}{ \# } & \multirow{2}{*}{$\begin{array}{c}\text { Technical solutions' } \\
\text { categories \& subcategories }\end{array}$} & \multirow[t]{2}{*}{ Concluded indicators } & \multicolumn{2}{|c|}{\begin{tabular}{|c|c} 
The relative \\
importance of the \\
Indicators
\end{tabular}} \\
\hline & & & \begin{tabular}{|l|} 
Max. \\
Points \\
\end{tabular} & Achieved \\
\hline \multirow[t]{7}{*}{1} & \multirow[t]{7}{*}{ Site selection } & \multirow{7}{*}{ 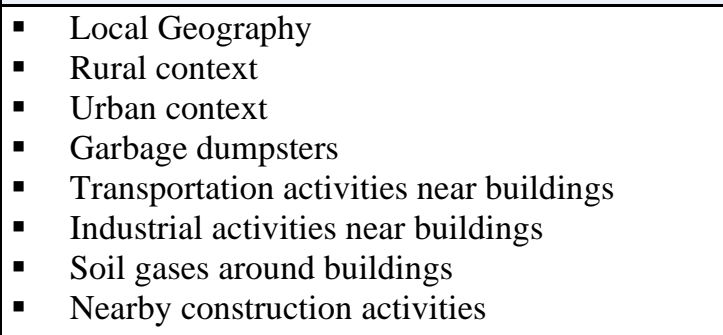 } & & \\
\hline & & & & \\
\hline & & & & \\
\hline & & & & \\
\hline & & & & \\
\hline & & & & \\
\hline & & & & \\
\hline 2 & Emissions control & & & \\
\hline \multirow[t]{7}{*}{2.1} & \multirow[t]{7}{*}{ VOC emissions } & \multirow{7}{*}{$\begin{array}{l}\text { - } \text { Furnishings } \\
\text { - } \text { Finishes } \\
\text { - } \text { Paints } \\
\text { - } \text { Adhesives } \\
\text { - } \text { Carpets } \\
\text { - } \text { Conrics } \\
\text { Concentrations remain }\end{array}$} & & \\
\hline & & & & \\
\hline & & & & \\
\hline & & & & \\
\hline & & & & \\
\hline & & & & \\
\hline & & & & \\
\hline \multirow[t]{8}{*}{2.2} & \multirow[t]{8}{*}{ Radon emissions } & \multirow{8}{*}{$\begin{array}{ll} & \text { Cracks in concrete slabs } \\
& \text { Spaces behind brick walls } \\
\text { - } & \text { Expoll joints } \\
\text { - } & \text { Leeping tile } \\
\quad & \text { Open tops of block walding materials, such as the rocks and water } \\
& \text { from the wells } \\
\end{array}$} & & \\
\hline & & & & \\
\hline & & & & \\
\hline & & & & \\
\hline & & & & \\
\hline & & & & \\
\hline & & & & \\
\hline & & & & \\
\hline \multirow[t]{3}{*}{2.3} & \multirow[t]{3}{*}{ Insulation materials' emissions } & \multirow{3}{*}{$\begin{array}{ll}\text { - } & \text { Formaldehyde producers } \\
\text { - } & \text { Toxic gases } \\
\text { - } & \text { Insulation materials }\end{array}$} & & \\
\hline & & & & \\
\hline & & & & \\
\hline \multirow[t]{6}{*}{2.4} & \multirow[t]{6}{*}{ Mineral fiber emissions } & \multirow{6}{*}{$\begin{array}{ll}\text { - } & \text { Facilities manufacturing } \\
\text { - } & \text { Glass wool fibers } \\
\text { - } & \text { Rlass filaments wool fibers } \\
\text { - } & \text { Slag wool fibers } \\
\text { - } & \text { Naturactory ceramic fentilation } \\
\end{array}$} & & \\
\hline & & & & \\
\hline & & & & \\
\hline & & & & \\
\hline & & & & \\
\hline & & & & \\
\hline 3 & $\begin{array}{l}\text { Ventilation and fresh air } \\
\text { delivery }\end{array}$ & & & \\
\hline \multirow[t]{7}{*}{3.1} & \multirow{6}{*}{$\begin{array}{l}\text { Outdoors's fresh air } \\
\text { contaminants }\end{array}$} & \multirow{6}{*}{ 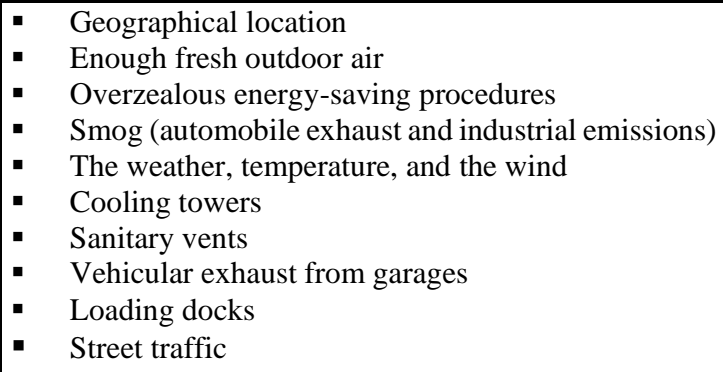 } & & \\
\hline & & & & \\
\hline & & & & \\
\hline & & & & \\
\hline & & & & \\
\hline & & & & \\
\hline & & - Adequate ventilation & & \\
\hline
\end{tabular}


JES, Assiut University, Faculty of Engineering, Vol. 45, No. 5, September 2017, pp. 722-741

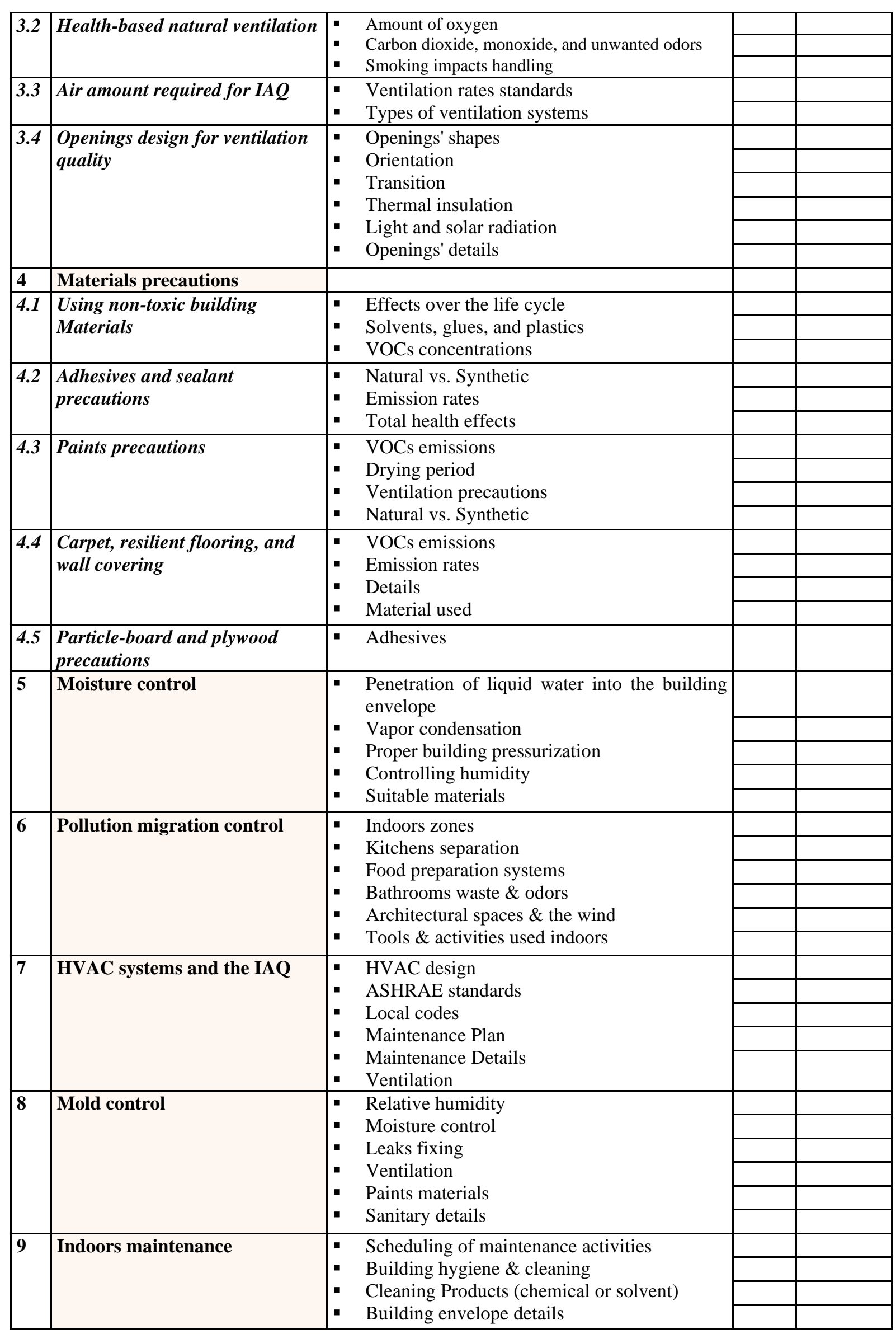


Usama Konbr, Studying the indoor air pollution within the residential buildings in Egypt .........

\subsubsection{The checklist's current applicability}

For individual or even teamwork of architects, sampling all above indicators is so unapproachable and overpriced, Specifically, when the scope of work extends to cover the whole country, as the Egyptian scope case. Where monitoring plan and a practical assessment strategy should be conducted as a base of air sampling, moreover, it needs researching duties in both short and long-term in various disciplines.

Locally, regarding the IAQ assessment's kinds of literature, just limited measurable parameters were selected according to their adverse impacts, Where Indoor air pollution indicators corresponded with specific parameters, which has clear measures for the projects. The essential factor in the quantitative assessment is the period of measurements. It may cause incorrect results if it is inadequate. So, both long-term sampling and monitoring are needed, with high cost and time load [45].

Moreover, the greatest serious and critical part of the assessment is existed, not only on environmental and engineering criteria but mainly, in the feelings and perceptions of occupants' needs. So, IAQ assessment must consider the vagueness, uncertainty, and doubt resulting from singular partialities with its incorrect results.

Regarding the checklist, it has various indicators. So, it is so complex to be tested in a real case study by individual effort. That, it surely needs a specific teamwork effort, with advanced \& scientific equipment. This complexity comes from the variety of biological, chemical, and physical indoor air aspects. Also, healthy, climatic, structural, mechanical, electrical, and systems disciplines are also factors; caring that analysis of the indicators can be branched into outside building causes, the building structure, and inside building causes. These are a vast range and cannot be done with only the architect's efforts.

The checklist is founded on the collaboration of a wide range of issues to be activated in the field area. Thus, it is necessary to establish a specific administration/ authority/ organization to cover all aspects in the activation phase and be an official tool. Hence, it can release the official \& scientific certificates to address and ensure the IAQ as an entry point to sustainability. This opinion is based on:

Setting the technical solutions' categories, subcategories, and the concluded adjustable indicators, all of these are still some flexible pre-thoughts. It can be accommodated precisely according to the professionals' variable and final opinion \& the specialist's teamwork. Setting the value of each indicator's relative importance needs special care and consensus opinions, particularly for multi-discipline indicators, considering that project locality is a crucial base in the assessment.

So, the paper in the current phase aims to summarize the indicators that influence the research problem. Furthermore, it opens the scope to more extensive efforts to complete the studying. Sure, it needs each specialist's sharing, where the measuring tools and missed data of architects will be replenished by others as well.

\subsubsection{The checklist's future applicability}

Globally, many institutes are growing the expertise on the IAQ concerns, specifying the urgencies, and aims that should be accomplished. These are activated by developing practical and methodical references of actions at each domestic level, considering the WHO's guidance (WHO) World Health Organization. 
Locally, by surveying, no single governmental organization in any authority has an obligation for the IAQ. Also, no rules or protocols have been developed precisely for the IEQ associated with architects or licenses awarding for the outdoor air.

So, for setting the proposed checklist in the activation phase, that needs also various nonarchitects specialists. Where every one of them will use his data to set:

a. The indicators: in extra details like principles, codes, and legislation.

b. The relative importance needs significant thoughts in harmony for formalizing the checklist as a tool, depending on more criteria, which varied from one project to another.

c. Maximum points reserved for each indicator: it is an important decision where its importance comes from the final assessment result related to the locality conditions and the renewable data.

So, the following recommendations can be emerged to activate the checklist:

- Suitable action should be taken to prepare a more detailed checklist or develop this one through a specific authority or administration on the national governmental level. It will be set for caring for the IEQ at all. As a paradigm, experiences of EPA, ASHRAE, and WHO can be taken.

- The housing and Building National Research Center (HBRC) can be a recommended affiliation with its potential. It can be either alone or in cooperation with other research authorities. That depends on the IAQ field's available specialists, the IAQ detailed criteria, and the set indicators.

- Also, the Egyptian Environmental Affairs Agency (EEAA) can be recommended to adopt this tool. It can be done by focusing on the IAQ from the architectural point of view. It needs to emit a new administration containing specialists in both architectural and environmental science.

- Magnifying the role of environmental labs in engineering research \& consultant centers, which exists at the faculties of engineering. Furthermore, promoting it to the extent where it can achieve more detailed studies \& results in this scope.

\section{Conclusion}

Concepts, categories, subcategories, strategies, and IAQ tradeoffs depend on possible conflicts among various solutions that can improve the building performance. The paper is a pushing step towards sustainability where it supports the IAQ study, with the particular emphasis on local needs to global environmental interests. Global IAQ assessment systems of performance and sustainability through their various packages contain standards, parameters, indicators, etc. All of these are based on fine details, depending on the locality criteria. Generally, assessment methods heavily rely on both professionals in various disciplines and occupants' claims, which international societies principally adopt. Hence, this represents a starting point of preparing similar handling for IAQ in the Egyptian's scope.

Subsequently, the extracted general framework in its two phases ensures the IAQ by studying indoor air pollution and considering the local environment's criteria. The study was divided into a theoretical part, followed by an extracted framework divided into two phases. Phase one addressed the technical solutions (the theoretical framework base), the second is the activation of it by proposing the evaluation tool (the checklist). It is a comprehensive, multidisciplinary assessment tool that assesses solution strategies through the theoretical part's derived indicators. Each indicator corresponds to a maximum number of points and the number of points achieved for each indicator. The evaluation depends on each indicator's relative importance, which relies 
Usama Konbr, Studying the indoor air pollution within the residential buildings in Egypt .........

on the overall vision of the multidisciplinary assessment teamwork, which conducts a comprehensive and final digital assessment score for IAQ projects.

The proposed checklist can be activated officially, through multidisciplinary teamwork, to release certificates. It can be implemented by a specific official authority or an administration. The certificates can be used as a part of the licensing requirements for new projects regarding IAQ. Also, the evaluators can use the checklist to assess the existing projects. Thus, its activation can magnify the integration of the key players needed to study indoor air pollution. At which the residential buildings will move towards sustainability.

\section{References}

[1] TEC Green Office, "Indoor air quality guidelines for Sydney Olympic facilities", Prepared for Green Games Watch 2000, Bondi Junction, Sydney, 1997, p. 9.

[2] Isam Khalafalla, "Indoor air quality in buildings", union international environmental solutions, caring for your health, 2012, p. 6.

[3] Lorena Gonzalez Navarro, "Indoor and outdoor air pollution", AVANZADO 2, 2013, p. 20.

[4] Hal Levin, "Integrating indoor air and design for sustainability", a paper presented at: indoor air 2005, Beijing, China, September 4-9, 2005.

[5] Terri Meyer Boake, "What is sustainable design?", part five: assessing green buildings. Associate director school of architecture, university of Waterloo, past president of the society of building science Educators, member OAA committee on sustainable built environment, 2009, p. 5.

[6] Tang G. Lee, "Health and the built environment: indoor air quality. Vital signs curriculum materials project", 1996, p. 10.

[7] Leadership in Energy and Environmental Design (LEED®), "LEED for new construction major renovations, rating system, version $2.2 ", 2005$, p. 13.

[8] David J. Nowak, "Tree species selection, design and management to improve air quality", ASLA annual meeting proceedings. USA: Washington, DC. ISSN 1090-7432, 2000, p. 3.

[9] David Fujiwara, "Indoor air quality assessment", safetech environmental limited, 2014, pp. 3-4.

[10] Oregon Certified Home Inspector, "Radon testing". Retrieved 8 August 2017 from http://www.orhomeinspections.com/radoneugene.

[11] N. Sai Bhaskar Reddy, "Indoor environmental quality of green building", green-building strategies for the mitigation of climate change, CCCEA, Dr. MCR human resource development institute of AP. At: 08-112011 to $10-11-2011$, pp. 32-33.

[12] Bowr, John, "Understanding ventilation, how to design, select and install residential ventilation systems", USA: Bloomington, healthy house institute. ISBN-13: 9780963715654, 1995.

[13] https://ntp.niehs.nih.gov.

[14] EPA's Integrated risk information system, "Fine mineral fibers". Retrieved 16 April 2017 from https://www.epa.gov/sites/production/files/2016-10/documents/fine-mineral-fibers.pdf. p. 1.

[15] William J. Fisk, "How IEQ affects health, productivity", article summary of Fisk, estimates the nationwide improvements in health and productivity. ASHRAE Journal, 2002.

[16] Lorena Gonzalez Navarro, "Indoor and outdoor air pollution", AVANZADO 2, 2013, pp. 7-9.

[17] P.S.S. TEJ, "Green buildings - topic indoor air quality", 2016, p. 14.

[ 18 ] N. Sai Bhaskar Reddy, "Green building design for sustainable urban habitats. Sustainable habitat management for clean development", CCCEA, Dr. MCR human resource development institute of AP, Hyderabad, 2012, p. 31.

[19] Usama Konbr, "Sustainability of the residential zones in the new urban communities in greater Cairo region, 
an approach for sustainability aspects assessment", Ph.D. thesis, submitted to the department of architecture, faculty of engineering, Al-azhar University, 2005, p. 118.

[20] Usama Konbr, Ibid.

[21] Hazim B. Awbi, "Ventilation of buildings", British library cataloguing in publication data. ISBN 0-20363782-8 (Adobe eReader Format), 2003, pp. 48-89, 97-121.

[22] Sanjay chaudhuri, "How to deal with sick building syndrome, a guide for employers, facility managers, building owners, building managers", shared services \& strategic facility management, 2010, p. 5.

[23] LEED®, "LEED for new construction major renovations, rating system, version 2.2", Op Cit, 2005 , p. 43.

[24] Jong-Jin Kim, "Sustainable architecture module: qualities, use and examples of sustainable building materials", Michigan: national pollution prevention center for higher education, 1998, p. 18.

[25] Isam Khalafalla, OP Cit, 2012, P. 11.

[26] Darrell W Pepper, "Modeling indoor air pollution", world scientific publishing Co. Pte. Ltd. ISBN-13 9781-84816-324-9, 2009, P. 36.

[27] EPA, "Energy savings plus health: indoor air quality guidelines for school building upgrades", USA, EPA 402/K-14/001, 2014, p. 7.

[28] LEED®, "LEED for new construction major renovations, rating system, version 2.2", Op Cit, 2005, p. 65.

[29] Thad Godish, "Indoor environmental quality", Lewis publishers is an imprint of CRC Press LLC, 2001.

[30] Jong-Jin Kim, "Sustainable architecture module: qualities, use and examples of sustainable building materials", Michigan: national pollution prevention center for higher education, 1998, p. 18.

[31] Darrell W Pepper, "Modeling indoor air pollution", world scientific publishing Co. Pte. Ltd. ISBN-13 9781-84816-324-9, 2009, p. 37.

[32] TEC Green Office, Op Cit, 1997, p. 23.

[33] ASHRAE, "Indoor air quality guide, best practices for design, construction and commissioning", ISBN: 978-1-933742-59-5. pp. 23, 75, 248, 417, 2009.

[34] Raymond J Cole, "Green building challenge 2000, GBC 2000 assessment manual : vol. 4: multi-unit residential buildings", school of architecture, university of British Columbia, 2000, p. 71.

[35] John P. Lapotaire, CICE, "Green building and indoor air quality", USA, Florida. Microshield environmental services LLC. Council certified indoor environmental quality consultant, 2009, p. 53.

[36] David Fujiwara, Op Cit, 2014, p. 2.

[37] Darrell W Pepper, Op Cit, 2009, p. 51.

[38] EPA. Op Cit, 2017, p. 3.

[39] United States Environmental Protection Agency (EPA). "Text version of the mold house tour". Retrieved 16 January 2017 from https://www.epa.gov/mold/text-version-mold-house-tour.

[40] Tang G. Lee, Op Cit, 1996, p. 19.

[41] P.S.S. TEJ, Op Cit, 2016, p. 12.

[42] Silvia Vilcekova, Eva Kridlova Burdova, "Rating of indoor environmental quality in systems of sustainability assessment of buildings", journal of civil engineering, environment, and architecture. JCEEA, t. XXXII, with. 62 (4/15), s. 459-467. 2015, p. 465.

[43] Wenjuan Wei el al, "Applicability and relevance of six indoor air quality indexes", Elsevier: published paper at the journal: Building and Environment, 109 (2016) 42e49, p. 1.

[44] Wenjuan Wei el al, Ibid.

[45] P.S. Hui, et al, "Feasibility study of a simple IAQ index for assessing air-conditioned offices", Facilities, Vol. 30 Issue: 3/4, pp. 124-134, https://doi.org/10.1108/02632771211202833, 2012. 


\section{دراسة تلوث الهواء داخل الفراغات السكنية في مصر كأحد عوامل الاستدامة}

المخدص

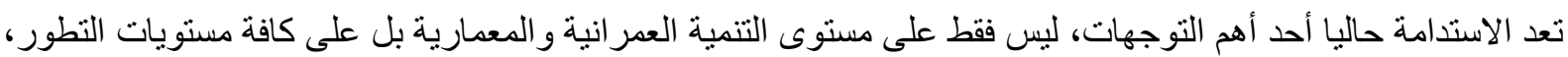

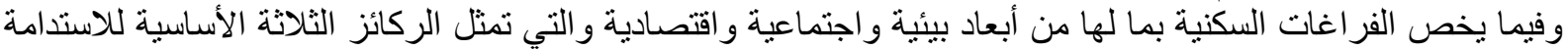

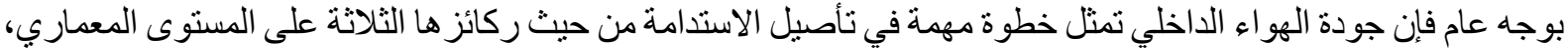

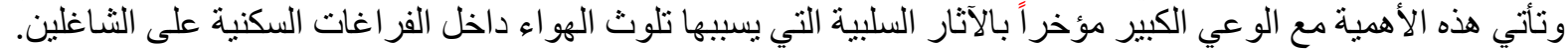

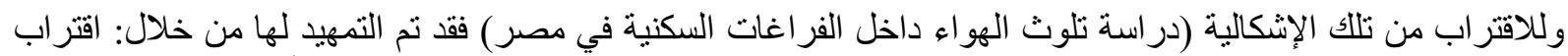

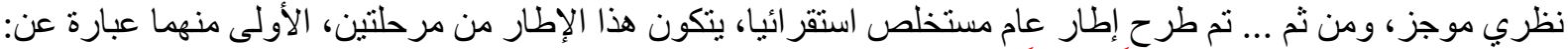

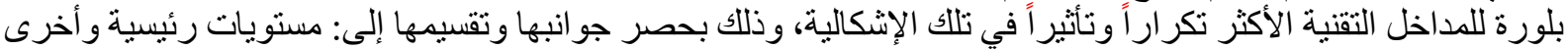

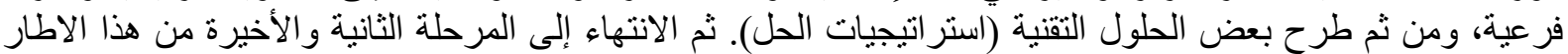

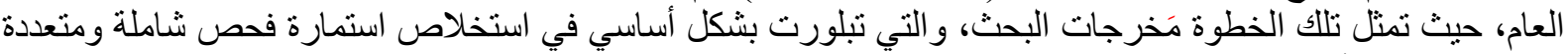

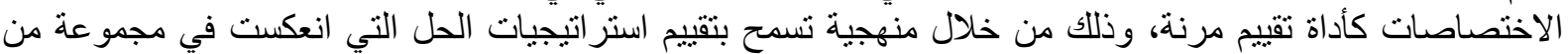

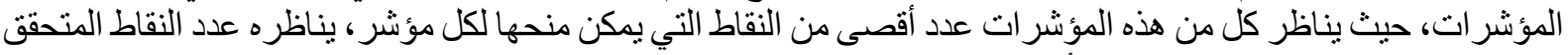

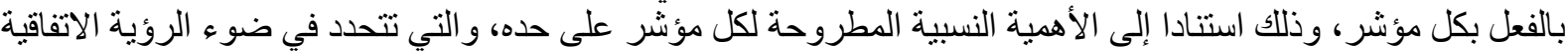

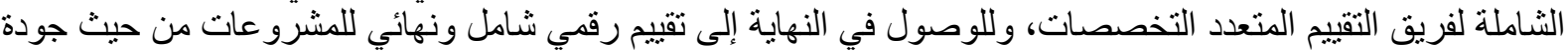
الهواء.

هذا ... ويمكن لاستمارة الفحص تللك أن تساعد كلاً من المصمين أو أو المقيمين على حد سو اءو، وذللك في كلٍ من مرحلة التصميم

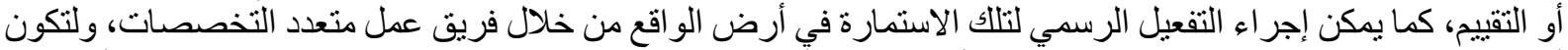

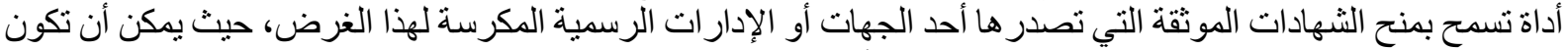

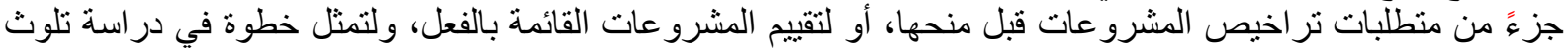
الهواء داخل الفر اغات السكنية في مصر كأحد عو امل الاستدامة. 